\title{
A Retrospective Analysis of Dose Distribution and Toxicity in Patients with Left Breast Cancer Treated with Adjuvant Intensity-Modulated Radiotherapy: Comparison with Three-Dimensional Conformal Radiotherapy
}

This article was published in the following Dove Press journal: Cancer Management and Research

\author{
Chia-Hsin Chen ${ }^{\prime}$ \\ Ching-Chuan Hsieh ${ }^{2}$ \\ Chih-Shen Chang' \\ Miao-Fen Chen (D) ${ }^{1,3}$ \\ 'Department of Radiation Oncology, \\ Chang Gung Memorial Hospital, Chiayi, \\ Taiwan; ${ }^{2}$ Department of General Surgery, \\ Chang Gung Memorial Hospital, Chiayi, \\ Taiwan; ${ }^{3}$ Chang Gung University College \\ of Medicine, Taoyuan City, Taiwan
}

Correspondence: Miao-Fen Chen Department of Radiation Oncology, Chang Gung Memorial Hospital at Chiayi, Chiayi, Taiwan

Email miaofen@adm.cgmh.org.tw
Background: A better understanding of the organs-at-risk (OAR) dose metrics and the related toxicity induced by radiotherapy (RT) for left breast cancer (BC) will improve the quality of life. This study addressed the issue for left-BC patients treated with intensity-modulated radiotherapy (IMRT) compared to three-dimensional conformal radiotherapy (3D-CRT).

Patients and Methods: Between 2012 and 2018, 308 left-BC patients underwent adjuvant RT at our hospital. Before June 2015, 134 patients were treated with 3D-CRT. Thereafter, 174 patients underwent IMRT. The patient's characteristics in the IMRT group did not significantly different compared to those in the 3D-CRT group.

Results: Among the total study population, the incidence of $\geq$ grade 2 radiation dermatitis (RID) was $17.3 \%$. Higher volumes receiving $105 \%(\geq 5.7 \%)$ and $107 \%(\geq 1 \%)$ of prescribed dose and 3D-CRT technique were associated with a higher risk of RID. Regarding lung toxicity, the mean lung dose $(\geq 10.2 \mathrm{~Gy})$ and V20 ( $\geq 20 \%)$ of ipsilateral lung were significantly associated with the incidence of RT-induced pulmonary changes. By dosimetry analysis, IMRT achieved better dose conformity and delivered lower mean doses to heart and ipsilateral lung compared to 3D-CRT. Furthermore, propensity sore and multivariate analysis showed that IMRT technique helped to reduce RT-induced dermatitis and lung toxicity.

Conclusion: Our data suggest that the volume of OAR exposed to higher doses is a predictor of RT-induced toxicity. Adjuvant RT with IMRT technique offered better dose conformity and spared high-dose levels to OARs to reduce radiation-related morbidity for BC patients.

Keywords: breast cancer, IMRT, 3D-CRT, OAR, toxicity

\section{Introduction}

Adjuvant radiotherapy (RT) substantially reduces recurrence rates of breast cancer (BC), and improves overall survival. ${ }^{1,2}$ However, RT-induced toxicities have been noted, including skin, lung and heart toxicity. ${ }^{1,3-5}$ Radiation dermatitis is the common clinical problem for BC patients receiving adjuvant $\mathrm{RT}^{6-8}$ Various RT techniques, such as intensity-modulated RT (IMRT), have been developed to improve dose conformity within the irradiated compared to conventional RT. ${ }^{9}$ IMRT delivers a more homogenous dose and may result in a lower rate of moist desquamation than conventional RT technique. ${ }^{10,11}$ We previously reported that an 
incidence of $23 \%$ for moist desquamation induced by three-dimensional conformal radiotherapy (3D-CRT) and the volume of hotspots was a predictor for the risk of moist desquamation. ${ }^{12}$ In the present study, we analyzed the RT dosimetry and the related dermatitis in Left-BC patients underwent IMRT compared to 3D-CRT.

In addition, RT-induced cardiopulmonary disease is correlated with the absorbed dose and irradiated volume. ${ }^{5,13}$ The higher the volume or the higher the dose of irradiated heart, the higher risk of developing ischemic heart disease. ${ }^{14} \mathrm{~A}$ linear relationship between the mean heart dose (MHD) and the rate of cardiac events was identified. ${ }^{15}$ Regarding lung toxicity, the irradiated volume exceeding a defined dose (Vdose), ipsilateral mean lung dose (MLD) and dose per fraction influenced the RTinduced lung morbidity. ${ }^{16-19} \mathrm{~A}$ better understanding of dosimetric parameters and its relationship with the incidence of RT-induced toxicity will help to improve the quality of life. Therefore, this study analyzed the exposures of organs-at-risk (OAR) dose metrics for left-BC patients underwent IMRT compared to those by 3D-CRT at our institution.

\section{Patients and Methods}

\section{Patients Characteristics of and Treatment Techniques}

This retrospective study was approved by the institutional review board of Chang Gung Memorial hospital (N0. 201900936B0), and a waiver of informed consent was obtained. This study adhered to strict confidentiality guidelines and in compliance with regulations regarding personal electronic data protection and the Declaration of Helsinki. There were 308 left-BC patients who completed the planned RT course from 2012 to 2018 enrolled into the study. Among these patients, 218 patients undergone breast-conserving surgery (BCS), and 90 patients received total mastectomy, then followed by adjuvant RT. Before June 2015, 134 patients received 3D-CRT. Thereafter, 174 patients underwent IMRT. In all, 282 patients had prophylactic skincare with moisture ointment every day from the beginning of RT. If required, adjuvant chemotherapy was performed sequentially rather than concurrently with radiotherapy in these patients (200 patients). Patients were observed at 3 weeks after the completion of RT, then 3-month intervals for the first 2 years and every 6 months thereafter. The Radiation Therapy Oncology Group (RTOG) scale was used to evaluate acute skin toxicity during the radiation treatment at weekly clinical examinations, and continued for 3 weeks after the end of radiotherapy. Grade 2 skin toxicity is described in the RTOG Acute Morbidity Scale as "tender or bright erythema, patchy moist desquamation/moderate edema", and Grade 3 "confluent moist desquamation other than skin folds, pitting edema". The correlation between acute radiation dermatitis (RID) and the examined risk factors were calculated as the percentage of patients with $\geq$ grade 2 skin toxicity. In addition, the radiation-induced lung injury was evaluated during and after radiation therapy. Clinically symptom was defined according to the modified Common Toxicity Criteria of the National Cancer Institute of Canada (CTC-NCIC). ${ }^{20}$ Chest computed tomography (CT) was evaluated 1-3 months after completion of radiation therapy. Density changes on chest CT were evaluated by comparing with the $\mathrm{CT}$ image prior to radiation therapy. Then chest X-ray films were performed annually during follow-up. If there were new abnormal findings found on Chest X-ray films, the patients would receive chest $\mathrm{CT}$ scan. An increase in density was graded according to a CT adapted modification of Arriagada's classification $(0=$ no change; $1=$ low opacity in linear streaks; $2=$ moderate opacity; 3 = complete opacity). ${ }^{19,21}$ The correlation between RT-induced pulmonary changes and the examined risk factors was calculated as the percentage of patients with $\geq$ grade 1 density change in CT scan.

\section{CT-Simulation and Radiotherapy Planning}

At the time of simulation, these left BC-patients underwent CT scans with free-breathing (FB), and the corresponding CT plans for adjuvant RT. In general, adjuvant RT was prescribed according to the planning target volume (PTV), which was $50 \mathrm{~Gy}$ in 25 fractions (268 patients) or $42.56 \mathrm{~Gy}$ in 16 fractions (40 patients). Of the 308 patients, 125 received simultaneous nodal irradiation. The skin, heart and ipsilateral lung were defined as OARs. The targets were delineated according to the Radiation Therapy Oncology Group (RTOG) breast cancer consensus definitions. ${ }^{22}$ The CTV was expanded by $10 \mathrm{~mm}$, but within $2 \mathrm{~mm}$ of the skin surface, to create the planned target volume (PTV) generated on the free-breathing CT scans. ${ }^{12,23,24}$ For patients who required simultaneous nodal irradiation, the supraclavicular lymph nodes were included into the CTV. The goal was to deliver $95 \%$ of the prescribed dose to at least $95 \%$ of the PTV while minimizing the dose delivered to the lung, heart, and contralateral breast. The dose constraint (in 2 Gy per fraction) of the volume of treatment volume (TV) receiving $110 \%$ of 
prescribed dose (V110\%) was $<5 \%$, of the heart was V25 Gy $<10 \%$, and the criteria for the ipsilateral lung was V20 $\leq 25 \%$; V5 Gy $\leq 50 \%$, for the whole lung was V20 $<20 \%$; V5 Gy $<30 \%$, and a minimized dose to the contralateral lung and breast. For patients treated with hypofractionation regimen, the dose to OARs was corrected. ${ }^{25}$ The 3D-CRT plans consisted of two major opposed open tangential half beams. Multileaf collimators (MLCs) were used to shield the heart, left lung and achieve the optimized dose distribution of the 3-dimensional plan. We usually used 1 2 additional segment ("field-in-field" technique) to further improve dose homogeneity and minimize the volume of radiation hotspots. Approximately $10 \%$ of the prescription dose was delivered with this shrunken field. The IMRT was a multi-beam (6-8 beams) step and shoot technique with a dose rate of $600 \mathrm{MU} /$ min. The gantry separation between ipsilateral fields ranged from $5^{\circ}$ to $10^{\circ}$. The multi-leaf collimator moving speed for beam delivery was set at $2.5 \mathrm{~cm}$ per second. The plans were generated from a full inverse planning system (Philips Pinnacle3 treatment planning system, Fitchburg, WI, USA) for optimization to generate the IMRT plan. We analyzed several parameters including PTV, the volume enclosed within the prescribed dose (TV), and the areas receiving an excessive dose such as V105\% and V107\% (percent volume receiving $105 \%$ and $107 \%$ of the prescribed dose, respectively). Figure 1A shows the isodose distribution of a representative patient, illustrating the radiation hotspots (V105\% and V107\%) related to the location of acute radiation dermatitis.

\section{Statistical Analyses}

Student's t-tests were utilized to analyze associations between RT-induced toxicity, dosimetric parameters and clinical characteristics, and to compare the dose distribution between the plans. Dose reduction to the OAR was compared between the 3D-CRT and IMRT plans. The p-value for a two-tailed test with a confidence interval of 95\% was used. Linear regression analyses were also performed using SPSS version 17.0. In addition, the propensity score method, which simulates the effects of a randomized trial for observational data, was used to estimate study outcomes. Inverse probability of treatment weighting (IPTW) of the propensity scores was used to create a pseudo-population in which study groups were balanced across covariates using data blinded to outcomes. Covariate balance was assessed using the standardized difference, which is the difference between groups divided by the pooled standard deviation, with a goal-to-achieve value $<0.1$.
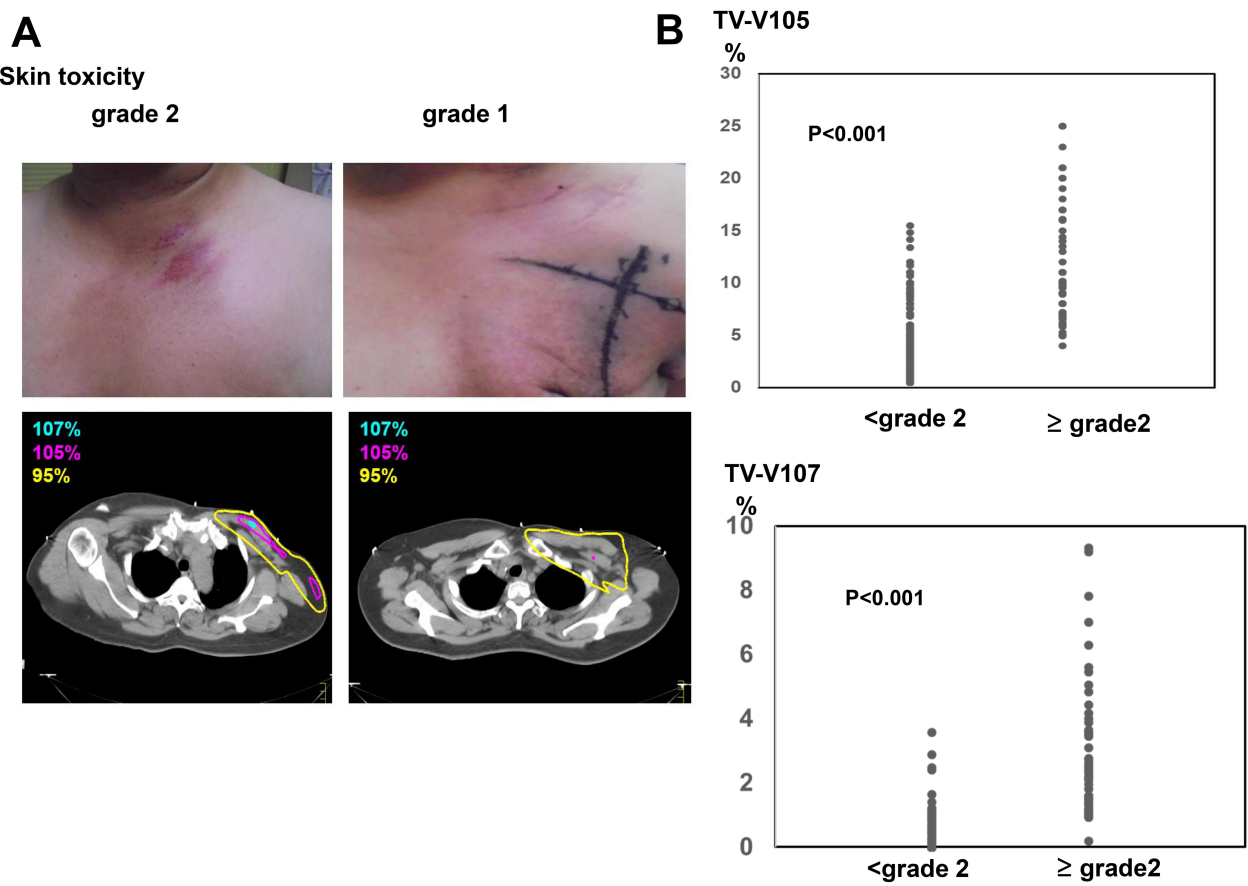

Figure I Radiation hotspots related to acute skin toxicity. (A) Representative pictures of selected patients with grade I and 2 acute skin toxicity, and the isodose distribution are shown, respectively (\% of prescribed dose: color curve; $95 \%$ : yellow curve; 105\%: pink curve; I07\%: light blue). (B) The volume of radiation hotspots in the groups of patients without and with radiation dermatitis. 


\section{Results}

\section{Patients and Acute Skin Toxicity}

All patients completed the planned course of treatment. The median age $( \pm \mathrm{SD})$ of the overall study population was $54 \pm$ 11 (range 24-88) years. The incidence of radiation dermatitis was $17.3 \%$ of the total study population. Among these 53 patients developed radiation dermatitis, 50 and 3 patients had grade 2 and 3 skin toxicity, respectively. Table 1 reveals that BMI $>24$, total mastectomy, and simultaneous nodal irradiation were associated with a higher incidence of $\geq$ grade 2 RID. The incidence of RID was $24 \%$ (22/90) in patients with total mastectomy compared to $14 \%(31 / 218)$ in those with BCS $(\mathrm{p}=0.031)$, and $9 \%(16 / 183)$ in those without nodal irradiation compared to $30 \%(37 / 125)$ in those with nodal irradiation $(p<0.001)$. We further analyzed the role of radiation hotspots in predicting acute skin toxicity. Figure 1B reveals that a higher volume of radiation hot spots were associated with a higher incidence of RID. To assess the predictive value of $\mathrm{V} 105 \%$ and $\mathrm{V} 107 \%$, they were redefined as a binary variable by finding the value from a receiveroperating characteristic (ROC) curve that maximized the percentage correctly classified for acute radiation dermatitis. Accordingly, we divided the patients into two groups for TVV105\% with $5.7 \%$ ( $92 \%$ sensitivity and $79 \%$ specificity), and TV-V107\% (98\% sensitivity and $80 \%$ specificity) with $1 \%$. As shown in Table 1, patients in the group with lower volumes of radiation hotspots had a significantly lower risk of developing radiation dermatitis compared to those with higher volumes of radiation hotspots.

\section{Skin Toxicity and Dosimetric Parameters for IMRT vs 3D-CRT}

We further divided the 308 patients into the group for 3DCRT and IMRT. Table 2 summarizes the patient numbers and the dosimetry parameters. A comparison of the parameters between the 2 groups revealed that the percentage of patients who had undergone a total mastectomy and nodal irradiation did not significantly differ. The patients treated with IMRT were at significantly lower risk for developing RID. The incidences of acute RID were $26 \%$ and $10 \%$ of the 3DRT and IMRT groups, respectively $(\mathrm{p}<0.001)$. A review of the IMRT dosimetry showed better target coverage with the volume of PTV and CTV receiving 95\% of the prescribed dose and dose conformality compared to the 3DCRT technique (Suppl. Figure 1). There were significantly lower volumes of radiation hotspots $(\mathrm{p}<0.001)$ in patients treated with IMRT compared to those treated with 3DRT. On
Table I Factors Correlated with the RT-Induced Skin Toxicity

\begin{tabular}{|c|c|c|c|}
\hline & \multicolumn{2}{|c|}{ Skin Toxicity } & \multirow[t]{2}{*}{$p$ value } \\
\hline & $<$ Grade 2 & $\geq$ Grade 2 & \\
\hline Patients & 255 (100\%) & $53(100 \%)$ & \\
\hline \multicolumn{4}{|l|}{ Age } \\
\hline Range & $24 \sim 88$ y/o & $30 \sim 80$ y/o & 0.81 \\
\hline Median & $54 y / 0$ & $53 y / 0$ & \\
\hline $\pm S D$ & 10.8 & 10.8 & \\
\hline BMI & & & $0.040 *$ \\
\hline$\leq 24$ & $126(49.4 \%)$ & 18 (34\%) & \\
\hline$>24$ & $129(50.6 \%)$ & $35(66 \%)$ & \\
\hline Surgery type & & & $0.031 *$ \\
\hline BCS & $187(73.3 \%)$ & 31 (58.5\%) & \\
\hline Mastectomy & $68(26.7 \%)$ & $22(41.5 \%)$ & \\
\hline RT technique & & & $<0.001 *$ \\
\hline 3D-CRT & 99 (38.8\%) & $35(66.0 \%)$ & \\
\hline IMRT & $156(61.2 \%)$ & $18(34.0 \%)$ & \\
\hline Nodal irradiation & & & $<0.001 *$ \\
\hline No & 167 (65.5\%) & $16(30.2 \%)$ & \\
\hline Yes & 88 (34.5\%) & 37 (69.8\%) & \\
\hline Prophylactic skin care & & & 0.78 \\
\hline No & $21(8.2 \%)$ & $5(9.4 \%)$ & \\
\hline Yes & 234 (91.8\%) & $48(90.6 \%)$ & \\
\hline \multicolumn{4}{|l|}{ Dosimetry (mean \pm SD) } \\
\hline CTV-V95\% & $98.91 \pm 0.1 \%$ & $98.6 \pm 0.2 \%$ & 0.137 \\
\hline PTV-V95\% & $95.9 \pm 0.1 \%$ & $94.6 \pm 0.3 \%$ & 0.135 \\
\hline TV-VI05\% & $3.7 \pm 0.2 \%$ & $11.6 \pm 0.8 \%$ & $<0.001 *$ \\
\hline$<5.7 \%$ & $200(78.4 \%)$ & $4(7.5 \%)$ & $<0.001 *$ \\
\hline$\geq 5.7 \%$ & $55(21.6 \%)$ & $49(92.5 \%)$ & \\
\hline TV-VI07\% & $0.2 \pm 0.03 \%$ & $2.8 \pm 0.3 \%$ & $<0.001 *$ \\
\hline$<1 \%$ & 239 (93.7\%) & $3(5.7 \%)$ & $<0.001 *$ \\
\hline$\geq 1 \%$ & $16(6.3 \%)$ & $50(94.3 \%)$ & \\
\hline
\end{tabular}

Notes: *Statistical significance. V105\% and V107\%=percent volume receiving $105 \%$ and $107 \%$ of the prescribed dose.

Abbreviations: BCS, breast-conserving surgery; BMI, body mass index; TV, treatment volume.

multivariate analysis for RID, patients received total mastectomy and 3D-CRT were associated with higher incidence of radiation dermatitis (Table 3).

\section{Dosimetric Parameters of OAR for IMRT vs 3DRT OAR Doses}

Table 4 summarizes the numbers of patients and the dosimetry parameters of heart and ipsilateral lung. Patients treated with IMRT had a significantly lower cardiac exposure, including the MHD and the V5 V20 based on the DVH for 
Table 2 Difference in Clinical Characteristics and Dosimetry Between IMRT and 3D-CRT Groups

\begin{tabular}{|c|c|c|c|}
\hline & \multicolumn{2}{|c|}{ RT Techniques } & \multirow{2}{*}{$p$ value } \\
\hline & 3DRT & IMRT & \\
\hline Patients & $134(100 \%)$ & 174 (I00\%) & \\
\hline BMI & & & 0.756 \\
\hline$\leq 24$ & $64(47.8 \%)$ & $80(46.0 \%)$ & \\
\hline$>24$ & 70 (52.2\%) & 94 (54.0\%) & \\
\hline Surgery type & & & 0.140 \\
\hline $\mathrm{BCS}$ & 89 (66.4\%) & $129(74.1 \%)$ & \\
\hline Mastectomy & 45 (33.6\%) & 45 (25.9\%) & \\
\hline Nodal irradiation & & & 0.885 \\
\hline No & 79 (59.0\%) & $104(59.8 \%)$ & \\
\hline Yes & 55 (4I.0\%) & 70 (40.2\%) & \\
\hline Skin toxicity & & & $<0.00 I^{*}$ \\
\hline$<$ grade 2 & 99 (73.9\%) & I56 (89.7\%) & \\
\hline$\geq$ grade 2 & $35(26.1 \%)$ & $18(10.3 \%)$ & \\
\hline Dosimetry (mean $\pm S D)$ & & & \\
\hline CTV-V95\% & $98.6 \pm 0.1 \%$ & $99 \pm 0.1 \%$ & $0.009^{*}$ \\
\hline PTV-V95\% & $94.5 \pm 0.2 \%$ & $95.2 \pm 0.1 \%$ & $0.001 *$ \\
\hline TV-V I05\% & $7.8 \pm 0.5 \%$ & $2.9 \pm 0.2 \%$ & $<0.001 *$ \\
\hline$<5.7 \%$ & $53(39.6 \%)$ & $15 \mid(86.8 \%)$ & $<0.00$ I* \\
\hline$\geq 5.7 \%$ & 81 (60.4\%) & $23(13.2 \%)$ & \\
\hline TV-V 107\% & $1.2 \pm 0.2 \%$ & $0.2 \pm 0.03 \%$ & $<0.001 *$ \\
\hline$<1 \%$ & $90(67.2 \%)$ & 152 (87.4\%) & $0.001 *$ \\
\hline$\geq 1 \%$ & $44(32.8 \%)$ & $22(12.6 \%)$ & \\
\hline
\end{tabular}

Notes: *Statistical significance. V105\% and V107\%=percent volume receiving $105 \%$ and $107 \%$ of the prescribed dose.

Abbreviations: BCS, breast-conserving surgery; BMI, body mass index; TV, treatment volume.

Table 3 Multivariate Analysis to Determine Factors Associated with RID

\begin{tabular}{|l|l|l|l|}
\hline Variable & HR & $\mathbf{9 5 \%} \mathbf{C l}$ & P value \\
\hline $\begin{array}{c}\text { Surgery type } \\
\text { Mastectomy } \\
\text { BCS }\end{array}$ & $\begin{array}{l}\text { Ref } \\
0.323\end{array}$ & $0.19-0.54$ & $<0.001 *$ \\
\hline $\begin{array}{l}\text { Nodal irradiation } \\
\text { Yes }\end{array}$ & Ref & & \\
No & 0.81 I & $0.60-1.1$ & 0.18 \\
\hline $\begin{array}{l}\text { BMI } \\
\leq 24\end{array}$ & Ref & & \\
$>24$ & 1.44 & $0.78-2.63$ & 0.24 \\
\hline $\begin{array}{l}\text { RT technique } \\
\text { 3D-CRT }\end{array}$ & Ref & & \\
IMRT & 0.27 & $0.14-0.50$ & $<0.00 I^{*}$ \\
\hline
\end{tabular}

Note: *Statistical significance.
Table 4 Dosimetric Differences Between 3D-CRT and IMRT for OAR

\begin{tabular}{|l|l|l|l|}
\hline \multicolumn{1}{|l|}{} & 3D-CRT & IMRT & p value \\
\hline Heart & & & \\
Dmean (Gy) & $5.31 \pm 0.20$ & $3.77 \pm 0.12$ & $<0.00 I^{*}$ \\
V5Gy (\%) & $16.5 \pm 0.8 \%$ & $13.9 \pm 0.6 \%$ & $0.014^{*}$ \\
VI0Gy (\%) & $10.6 \pm 0.6 \%$ & $7.6 \pm 0.4 \%$ & $<0.00 I^{*}$ \\
V20Gy (\%) & $7.7 \pm 0.4 \%$ & $4.6 \pm 0.2 \%$ & $<0.00 I^{*}$ \\
\hline Left Lung & & & \\
Dmean (Gy) & $11.28 \pm 0.28$ & $10.40 \pm 0.3$ & $0.039 *$ \\
$<10.2 G y$ & 52 & 101 & $0.00 I^{*}$ \\
$\geq 10.2 G y$ & 82 & 73 & \\
V20Gy (\%) & $21.6 \pm 0.6$ & $19.8 \pm 0.4$ & $0.024^{*}$ \\
$<20 \%$ & 58 & 98 & $0.023^{*}$ \\
$\geq 20 \%$ & 76 & 76 & \\
V5Gy (\%) & $38.6 \pm 0.7$ & $36.6 \pm 0.6$ & 0.051 \\
\hline
\end{tabular}

Note: *Statistical significance.

the CT treatment plans. Patient variability was noted in terms of the MHD with a range of values from 1.22 to 16 Gy $(4.4 \pm 0.12 \mathrm{~Gy})$. The distance of heart (DHL) is measured on the CT slice with the thickest section of heart and is defined as the distance between the anterior cardiac contour to the imaginary line connecting middle point of sternum and the left middle axillary line (Figure 2A). Figure 2B reveals that there was a positive correlation between the MHD and DHL $(\mathrm{R}=0.66)$. To assess the predictive value of the DHL, DHL was redefined as a binary variable by finding the value from a ROC curve that maximized the percentage correctly classified for predicting MHD $\geq 4.4 \mathrm{~Gy}$. The optimal cut-off for the DHL was $2.47 \mathrm{~cm}$ (79\% sensitivity and $62 \%$ specificity). Accordingly, we divided the patients into high and low-DHL groups. The MHD was $3.42 \pm 0.10 \mathrm{~Gy}$ in the low-DHL group and $5.48 \pm 0.18 \mathrm{~Gy}$ in the high-DHL group. IMRT significantly reduced the MHD both in both groups of DHL $(\mathrm{p}<0.001)$ compared to those treated with 3D-CRT (Suppl. Figure 2). Furthermore, treatment with IMRT was associated with a lower mean dose, and V20 of the ipsilateral lung. The mean lung dose values for the 3D-CRT and IMRT groups were $11.3 \pm 0.3 \mathrm{~Gy}$ and $10.4 \pm 0.3 \mathrm{~cm}^{3}$, respectively $(\mathrm{p}=0.039)$.

\section{Clinical Findings}

There were no deaths related to cardiac toxicity or major coronary events during the follow-up. The median followup time was 51.7 months (range 2.7-112.3 months). In term of lung toxicity, no patients had grade 2 symptomatic radiation pneumonitis during the follow-up. The most 
A

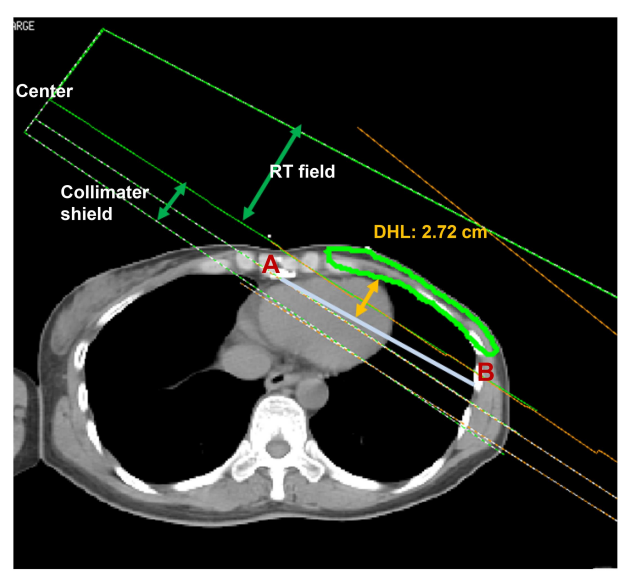

B

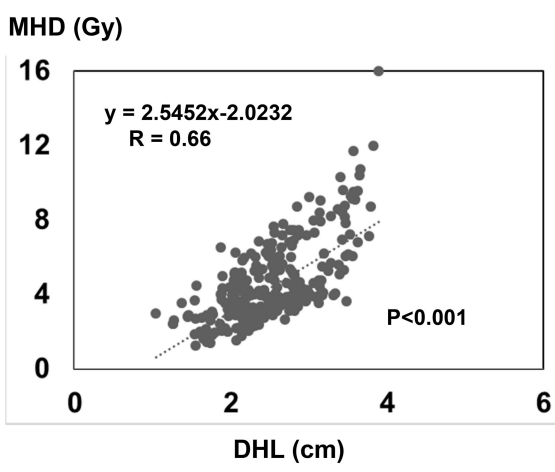

Figure 2 Relationship between MHD and the distance of heart (DHL) for left-sided breast cancer patients. (A) Representative images of the distance of heart (DHL) is shown (A: the midline of the sternum; B: the left middle axillary line; DHL: orange; PTV: light green). (B) The values of DHL plotted against mean heart dose. DHL indicated good positive linear correlation with mean heart dose for all patients.

common pulmonary changes in the imaging included patchy, ground-glass opacities, and fibrosis. In all, 81 patients (26\%) developed radiographic changes within the RT field in follow-up images (Figure 3, Table 5). The data revealed that total mastectomy, simultaneous nodal irradiation, and 3D-CRT technique were associated with a higher risk of developing RT-induced radiologic changes. The incidence was $41 \%(37 / 90)$ in patients with a total mastectomy compared to $20 \%(44 / 218)$ in patients who had undergone BCS $(p<0.001)$, and $17 \%(31 / 183)$ in patients without nodal irradiation compared to $40 \%(50 / 125)$ in patients with nodal irradiation $(\mathrm{p}<0.001)$. Furthermore, RTinduced pulmonary changes occurred in $34 \%$ and $20 \%$ of the 3D-CRT and IMRT groups, respectively. The MLD and the ipsilateral lung V20 were, the important predictors of radiation pneumonitis, being significantly associated with incidence of developing RT-induced pulmonary changes. We used the median of MLD (10.2 Gy) and V20 $(20 \%)$ as a cut-off value to divide the 308 patients into lower and higher groups. The patients in the lower MLD and V20 group had a significantly lower risk for developing RT-induced pulmonary injury compared to those in the higher groups. Furthermore, there were significantly more patients who had undergone 3D-CRT in the higher MLD and V20 group compared to those treated with IMRT. By multivariate analysis, patients received total mastectomy and 3D-CRT was associated with higher incidence of RT-induced pulmonary changes (Table 6).

\section{Propensity Score Analysis}

To further corroborate the results observed in the whole series, a propensity score analysis was performed. After IPTW adjustment, the distributions of most demographic and clinicopathological characteristics were similar
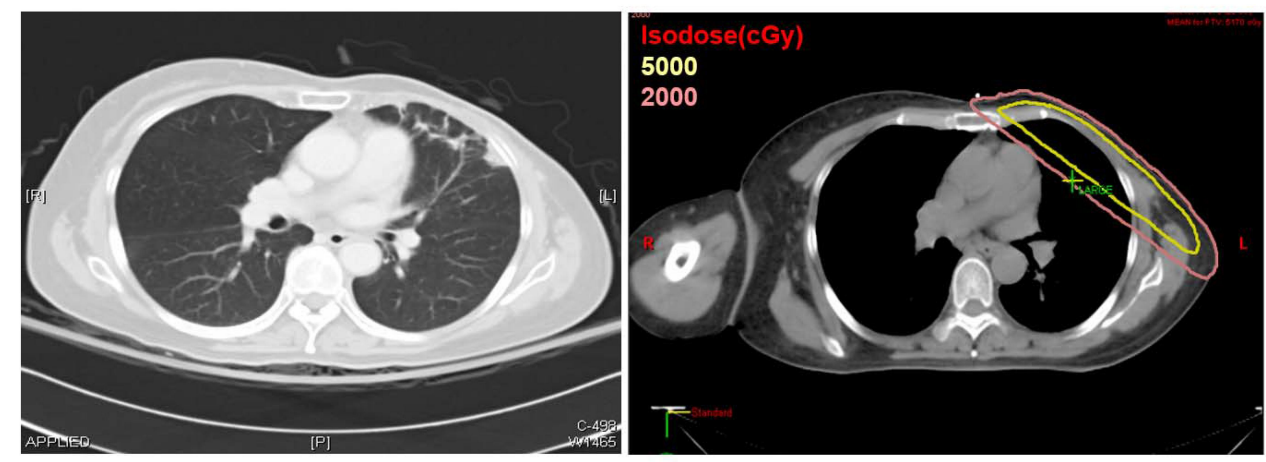

Figure 3 Relationship between RT-induced radiologic changes and V20 of ipsilateral lung Representative pictures of a selected patient with RT-induced radiologic changes and the isodose distribution are shown, respectively (prescribed dose: yellow curve; V20: orange curve). 
Table 5 Factors Correlated with the RT-Induced Radiologic Changes for Ipsilateral Lung

\begin{tabular}{|c|c|c|c|}
\hline & \multicolumn{2}{|c|}{ Pulmonary Changes } & \multirow{2}{*}{$p$ value } \\
\hline & $(-)$ & $(+)$ & \\
\hline Patients & 227 (100\%) & 81 (100\%) & \\
\hline BMI & & & 0.38 \\
\hline$\leq 24$ & III (48.9\%) & 35 (43.2\%) & \\
\hline$>24$ & $116(51.1 \%)$ & $46(56.8 \%)$ & \\
\hline Surgery type & & & $<0.001$ \\
\hline $\mathrm{BCS}$ & $174(76.7 \%)$ & 44 (54.3\%) & \\
\hline Mastectomy & $53(23.3 \%)$ & $37(45.7 \%)$ & \\
\hline RT technique & & & $0.005^{*}$ \\
\hline 3DRT & $88(38.7 \%)$ & $46(56.8 \%)$ & \\
\hline IMRT & 139 (61.2\%) & $35(43.2 \%)$ & \\
\hline Nodal irradiation & & & $<0.00 I^{*}$ \\
\hline No & $152(67.0 \%)$ & 31 (38.3\%) & \\
\hline Yes & 75 (33.0\%) & $50(61.7 \%)$ & \\
\hline Dosimetry (mean $\pm S D$ ) & & & \\
\hline MLD (Gy) & $10.32 \pm 0.25$ & $12.09 \pm 0.34$ & $<0.001 *$ \\
\hline$<10.2 \mathrm{~Gy}$ & $130(57.3 \%)$ & $23(28.4 \%)$ & \\
\hline$\geq 10.2 \mathrm{~Gy}$ & 97 (42.7\%) & 58 (71.6\%) & \\
\hline V20Gy (\%) & $19.6 \pm 0.4 \%$ & $23.5 \pm 0.7 \%$ & $<0.00$ I* \\
\hline$<20 \%$ & $129(56.8 \%)$ & 27 (33.3\%) & \\
\hline$\geq 20 \%$ & $98(43.2 \%)$ & $54(66.7 \%)$ & \\
\hline
\end{tabular}

Note: *Statistical significance.

Abbreviations: BCS, breast-conserving surgery; BMI, body mass index; MLD, mean lung dose.

Table 6 Multivariate Analysis to Determine Factors Associated with RT-Induced Pulmonary Injury

\begin{tabular}{|l|l|l|l|}
\hline Variable & HR & 95\% Cl & P value \\
\hline $\begin{array}{c}\text { Surgery type } \\
\text { Mastectomy } \\
\text { BCS }\end{array}$ & $\begin{array}{l}\text { Ref } \\
0.343\end{array}$ & $0.22-0.54$ & $<0.00)^{*}$ \\
\hline $\begin{array}{c}\text { Nodal irradiation } \\
\text { Yes } \\
\text { No }\end{array}$ & Ref & & \\
\hline $\begin{array}{c}\text { BMI } \\
\leq 24 \\
>24\end{array}$ & 0.802 & $0.53-1.22$ & 0.31 \\
\hline $\begin{array}{c}\text { MLD (Gy) } \\
<10.2 G y \\
\geq 10.2 G y\end{array}$ & Ref & & \\
\hline $\begin{array}{c}\text { RT technique } \\
\text { 3D-CRT }\end{array}$ & 1.16 & $0.68-1.98$ & 0.58 \\
IMRT & Ref & $0.98-3.45$ & 0.06 \\
\hline
\end{tabular}

Note: *Statistical significance. between the 3D-CRT and IMRT groups. The effect of the adjustment is depicted in Table 7. The analyses showed that IMRT was associated with significant benefits for the reduction of RID and RT-induced pulmonary changes after adjustment by IPTW (Table 8).

\section{Discussion}

In recent years, promising RT techniques have been developed to improve dose conformality and homogeneity for BC patients. However, the correlation between dosimetric parameters and the incidence of radiation-induced OAR toxicity requires further investigation. First, we examined the incidence of radiation dermatitis and its relationship with volume of radiation hotspots and RT techniques. According to previous finding, ${ }^{12}$ we applied the constraint of $\mathrm{TV}-\mathrm{V} 110 \%<5 \%$ in treatment planning for BC. As a result, the incidence of grade 3 skin toxicity decreased from $1.9 \%$ to $1 \%$ compared to that our previous study. We suggest that further significant advancements in conformal treatment delivery have helped to reduce the volume exposed to higher doses; this in turn has resulted in decreased toxicity outcomes. In the present study, we demonstrated that the larger volumes of radiation hotpots (TV-V105\% and V107\%) were significant predictors of radiation dermatitis. Furthermore, we demonstrated that IMRT significantly improved dose inhomogeneity and decreased volumes of radiation hotspots compared with 3D-CRT. In addition to dose parameters, we found that BMI $>24$, total mastectomy, and simultaneous nodal irradiation were associated with a higher incidence of radiation dermatitis. There are still no well-established prophylactic treatments available to prevent RT-induced skin toxicity. ${ }^{26}$ We previously reported that prophylactic skincare significantly attenuated the risk of radiation dermatitis. ${ }^{12}$ Greater than $90 \%$ of patients in the study received prophylactic skin treatment. It may explain why the use of prophylactic treatment did not significantly decrease the incidence of radiation dermatitis in the present study.

The lung is sensitive to radiation and side effects may arise, as acute pneumonitis and late lung fibrosis. RTinduced lung toxicity may arise, either acutely or as a chronic disorder following RT. ${ }^{27-29}$ Clinically, symptomatic RP is one of the major toxicity for irradiated $\mathrm{BC}$ patients. ${ }^{30}$ In our study, none of the patients developed significant symptomatic RP, but there were 81 patients (26\%) did develop radiographic changes within RT field, as noted in follow-up images. In the present study, total 
Table 7 Baseline Characteristics for Unweighted Sample and Inverse Probability of Treatment-Weighted (IPTW-ATE) Sample

\begin{tabular}{|c|c|c|c|c|c|c|}
\hline \multirow[t]{2}{*}{ Variables } & \multicolumn{2}{|c|}{ Unweighted Sample } & \multirow{2}{*}{$\begin{array}{l}\text { Standardized Mean } \\
\text { Difference }\end{array}$} & \multicolumn{2}{|l|}{ IPTW-ATE } & \multirow{2}{*}{$\begin{array}{l}\text { Standardized Mean } \\
\text { Difference }\end{array}$} \\
\hline & $\begin{array}{l}\text { 3D-CRT } \\
(n=134)\end{array}$ & $\begin{array}{l}\text { IMRT } \\
(n=174)\end{array}$ & & $\begin{array}{l}\text { 3D-CRT } \\
(n=307)\end{array}$ & $\begin{array}{l}\text { IMRT } \\
(n=308)\end{array}$ & \\
\hline Age (mean, SD) & $54.9(10.6)$ & $55.5(10.9)$ & 0.053 & $55.1(15.8)$ & $55.1(14.4)$ & 0.006 \\
\hline $\begin{array}{c}\text { BMI (\%) } \\
\quad \leq 24 \\
>24\end{array}$ & $\begin{array}{l}64(47.8) \\
70(52.2)\end{array}$ & $\begin{array}{l}80(46.0) \\
94(54.0)\end{array}$ & -0.036 & $\begin{array}{l}144(46.9) \\
163(53.1)\end{array}$ & $\begin{array}{l}144(46.8) \\
164(53.2)\end{array}$ & -0.006 \\
\hline $\begin{array}{l}\text { Surgery type (\%) } \\
\text { BCS } \\
\text { Mastectomy }\end{array}$ & $\begin{array}{l}89(66.4) \\
45(33.6)\end{array}$ & $\begin{array}{l}129(74.1) \\
45(25.9)\end{array}$ & -0.170 & $\begin{array}{l}217(70.8) \\
90(29.2)\end{array}$ & $\begin{array}{l}218(70.9) \\
90(29.1)\end{array}$ & 0.005 \\
\hline $\begin{array}{l}\text { Nodal irradiation (\%) } \\
\text { No } \\
\text { Yes }\end{array}$ & $\begin{array}{l}79(59.0) \\
55(41.0)\end{array}$ & $\begin{array}{l}104(59.8) \\
70(40.2)\end{array}$ & 0.016 & $\begin{array}{l}183(59.4) \\
124(40.6)\end{array}$ & $\begin{array}{l}183(59.5) \\
125(40.5)\end{array}$ & 0.005 \\
\hline $\begin{array}{l}\text { Hypofraction (\%) } \\
\text { No } \\
\text { Yes }\end{array}$ & $\begin{array}{l}112(83.6) \\
22(16.4)\end{array}$ & $\begin{array}{l}156(89.7) \\
18(10.3)\end{array}$ & 0.179 & $\begin{array}{l}267(86.9) \\
40(13.1)\end{array}$ & $\begin{array}{l}268(87.0) \\
40(13.0)\end{array}$ & -0.010 \\
\hline
\end{tabular}

Table 8 Odds Ratios for Study Outcomes Between IMRT and 3D-CRT Groups by Different Analysis Approaches

\begin{tabular}{|c|c|c|c|c|}
\hline & \multicolumn{2}{|c|}{ Acute Skin Toxicity } & \multicolumn{2}{|c|}{ Toxicity (Chest-Lung) } \\
\hline & OR (95\% Cl) & $P$-value & OR $(95 \% \mathrm{Cl})$ & $P$-value \\
\hline \multicolumn{5}{|c|}{ Unweighted Sample } \\
\hline RT type & & & & \\
\hline 3D-CRT & Reference & - & Reference & - \\
\hline IMRT & $0.26(0.13-0.5 \mathrm{I})$ & $<0.001$ & $0.47(0.27-0.80)$ & 0.006 \\
\hline \multicolumn{5}{|c|}{ IPTW-ATE } \\
\hline RT type & & & & \\
\hline 3D-CRT & Reference & - & Reference & - \\
\hline IMRT & $0.24(0.15-0.40)$ & $<0.001$ & $0.46(0.3 I-0.67)$ & $<0.001$ \\
\hline
\end{tabular}

Note: Models were adjusted by age, BMl group, surgery type, and nodal irradiation.

mastectomy and adding regional nodal irradiation were associated with a higher risk for developing RT-induced radiological changes. The risk for RT-induced lung toxicity is reported to be influenced by the irradiated lung volume, dose and RT field. ${ }^{31,32}$ The incidence of pulmonary complications in adjuvant 3D-CRT for BC is clinically significant. $^{33}$ We demonstrated that IMRT significantly decreased the incidence of RT-induced pulmonary changes from $34 \%$ in 3 D-CRT to $20 \%$ in IMRT. With today's CTbased-planning techniques, we can individually quantify and limit the amount of incidentally irradiated lung volume. $^{16}$ The MLD and the ipsilateral lung V20 were reported to be critical to induce RP in cancer patients with lung irradiation ${ }^{34,35}$. For left-BC patients with RT, we demonstrated that MLD and V20 of the ipsilateral lung were significantly associated with the risk of developing RT-induced pulmonary changes. We further used the median value of by MLD (10.2Gy) and V20 (20\%) to divide the 308 patients into lower and higher groups. The data revealed that both $\mathrm{V} 20<20 \%$ and MLD $<10.2 \mathrm{~Gy}$ for ipsilateral lung were associated with significantly lower RT-induced radiologic changes. Based on our data, individual CT-based dose planning and dosimetric analysis of ipsilateral lung is important for the reduction of RTinduced lung injury.

It has described that adjuvant RT contributed to the induction of ischemic heart disease for left-sided BC population. ${ }^{15,36} \mathrm{~A}$ comparison of all patients in our series revealed that $\mathrm{BMI}>24$, total mastectomy and nodal irradiation were significantly associated with increased MHD. It has been reported that variations in chest shape can impact the cardiopulmonary dose received. ${ }^{37,38}$ In the present study, there was a positive correlation between the MHD and DHL. The patients with DHL $\geq 2.47 \mathrm{~cm}$ were associated with higher MHD compared to those lower DHL. As the incidence of ischemic heart disease is proportional to the MHD, ${ }^{14,39}$ it was advised a reduction of the dose to the heart by as much as possible. Furthermore, the risk of cardiac events is likely to be related to dose and irradiated 
volume. ${ }^{25,40}$ In our study, patients treated with IMRT had significantly lower MHD associated with reduced the irradiated volume and dose in the heart for left-BC patients compared to 3D-CRT.

In the present study, the benefits of IMRT compared to conventional 3D have been evaluated. Dosimetry studies have shown that IMRT results in similar target volume coverage, better conformity, and a reduced volume of normal tissues that are irradiated at a high dose. Dosimetric studies showed that volumetric modulated arc therapy (VMAT) also improved target volume coverage and delivered better dose homogeneity. ${ }^{14}$ The potential risk existing in IMRT and VMAT are that these techniques expose the heart to a substantial "low dose bath" from multiple beam angles. Furthermore, research has shown a further reduction in cardiac exposure by implementing respiratory management methods during radiation delivery, such as deep inspiration breath hold (DIBH). In our preliminary study, ${ }^{23}$ a regimen using IMRT and DIBH resulted in a significantly lower MHD and Dmean of the LAD compared to FB plans for left BC. However, there were variability of dose reductions by $\mathrm{DIBH}$, and not all patients receive the same benefit from the DIBH technique. In general, choosing which kind (one or more) of methods to use is mainly based on individual characteristics and RT regions. Therefore, to enroll more left-BC patients using IMRT and DIBH would be helpful to find factors to identify which patients derive the most benefit from the IMRT and DIBH technique. The main limitation of this study was that was retrospective in nature and lacked data on long term follow-up for cardiopulmonary toxicity. Therefore, longer follow-up and further investigations that include more patients in a prospective trial are needed.

\section{Conclusion}

In general, the choice of adjuvant RT, and the type of methods used are mainly based on individual characteristics and target regions. Our data suggest that IMRT spared high-dose levels to OARs, and offers better dose conformity than 3D-CRT technique for left-BC patients.

\section{Acknowledgment}

The authors thank Meng-Hung Lin, PhD and Health Information and Epidemiology Laboratory, Chang Gung Memorial Hospital, Chiayi Branch for providing comments and assistance in data analysis.

\section{Disclosure}

The authors declare that they have no competing interests for this work.

\section{References}

1. Clarke M, Collins R, Darby S, et al. Effects of radiotherapy and of differences in the extent of surgery for early breast cancer on local recurrence and 15-year survival: an overview of the randomised trials. Lancet. 2005;366:2087-2106.

2. McGale P, Taylor C, Correa C, et al. Effect of radiotherapy after mastectomy and axillary surgery on 10-year recurrence and 20-year breast cancer mortality: meta-analysis of individual patient data for 8135 women in 22 randomised trials. Lancet. 2014;383:2127-2135. doi:10.1016/S0140-6736(14)60488-8

3. Darby SC, McGale P, Taylor CW, Peto R. Long-term mortality from heart disease and lung cancer after radiotherapy for early breast cancer: prospective cohort study of about 300,000 women in US SEER cancer registries. Lancet Oncol. 2005;6:557-565. doi:10.10 16/S1470-2045(05)70251-5

4. Matzinger O, Heimsoth I, Poortmans $\mathrm{P}$, et al. Toxicity at three years with and without irradiation of the internal mammary and medial supraclavicular lymph node chain in stage I to III breast cancer (EORTC trial 22922/10925). Acta Oncol. 2010;49:24-34. doi:10.31 $09 / 02841860903352959$

5. Gagliardi G, Lax I, Rutqvist LE. Partial irradiation of the heart. Semin Radiat Oncol. 2001;11:224-233. doi:10.1053/srao.2001.23 483

6. Kole AJ, Kole L, Moran MS. Acute radiation dermatitis in breast cancer patients: challenges and solutions. Breast Cancer (Dove Med Press). 2017;9:313-323.

7. Lee J, Park W, Choi DH, et al. Patient-reported symptoms of radiation dermatitis during breast cancer radiotherapy: a pilot study. Qual Life Res. 2017;26:1713-1719. doi:10.1007/s11136-017-1526-4

8. Chan RJ, Larsen E, Chan P. Re-examining the evidence in radiation dermatitis management literature: an overview and a critical appraisal of systematic reviews. Int J Radiat Oncol Biol Phys. 2012;84:e357e362. doi:10.1016/j.ijrobp.2012.05.009

9. Barnett GC, Wilkinson JS, Moody AM, et al. Randomized controlled trial of forward-planned intensity modulated radiotherapy for early breast cancer: interim results at 2 years. Int J Radiat Oncol Biol Phys. 2012;82:715-723. doi:10.1016/j.ijrobp.2010.10.068

10. Pignol J-P, Olivotto I, Rakovitch E, et al. A multicenter randomized trial of breast intensity-modulated radiation therapy to reduce acute radiation dermatitis. J Clin Oncol. 2008;26(13):2085-2092. doi:10.12 00/JCO.2007.15.2488

11. Morganti AG, Cilla S, Valentini V, et al. Phase I-II studies on accelerated IMRT in breast carcinoma: technical comparison and acute toxicity in 332 patients. Radiother Oncol. 2009;90:86-92. doi:10.1016/j.radonc.2008.10.017

12. Chen MF, Chen WC, Lai $\mathrm{CH}$, Hung $\mathrm{CH}$, Liu $\mathrm{KC}$, Cheng $\mathrm{YH}$. Predictive factors of radiation-induced skin toxicity in breast cancer patients. BMC Cancer. 2010;10:508. doi:10.1186/1471-2407$10-508$

13. Qi XS, Hu A, Wang K, et al. Respiration induced heart motion and indications of gated delivery for left-sided breast irradiation. Int J Radiat Oncol Biol Phys. 2012;82:1605-1611. doi:10.1016/j. ijrobp.2011.01.042

14. Zhu Q, Kirova YM, Cao L, Arsene-Henry A, Chen J. Cardiotoxicity associated with radiotherapy in breast cancer: a question-based review with current literatures. Cancer Treat Rev. 2018;68:9-15. doi:10.1016/j.ctrv.2018.03.008

15. Darby SC, Ewertz M, McGale P, et al. Risk of ischemic heart disease in women after radiotherapy for breast cancer. $N$ Engl $J$ Med. 2013;368:987-998. doi:10.1056/NEJMoa1209825 
16. Blom Goldman U, Anderson M, Wennberg B, Lind P. Radiation pneumonitis and pulmonary function with lung dose-volume constraints in breast cancer irradiation. J Radiother Pract. 2014;13: 211-217. doi:10.1017/S1460396913000228

17. Mansouri S, Naim A, Glaria L, Marsiglia H. Dosimetric evaluation of 3-D conformal and intensity-modulated radiotherapy for breast cancer after conservative surgery. Asian Pac J Cancer Prev. 2014;15:4727-4732. doi:10.7314/APJCP.2014.15.11.4727

18. Mayo CS, Urie MM, Fitzgerald TJ. Hybrid IMRT plans-concurrently treating conventional and IMRT beams for improved breast irradiation and reduced planning time. Int $J$ Radiat Oncol Biol Phys. 2005;61:922-932. doi:10.1016/j.ijrobp.2004.10.033

19. Lee TF, Chao PJ, Chang L, Ting HM, Huang YJ. Developing multivariable normal tissue complication probability model to predict the incidence of symptomatic radiation pneumonitis among breast cancer patients. PLoS One. 2015;10:e0131736.

20. Trotti A, Colevas AD, Setser A, et al. CTCAE v3.0: development of a comprehensive grading system for the adverse effects of cancer treatment. Semin Radiat Oncol. 2003;13:176-181. doi:10.1016/ S1053-4296(03)00031-6

21. Arriagada R, de Guevara J, Ladron C, et al. Limited small cell lung cancer treated by combined radiotherapy and chemotherapy: evaluation of a grading system of lung fibrosis. Radiother Oncol. 1989;14:1-8. doi:10.1016/0167-8140(89)90002-9

22. Fontanilla HP, Woodward WA, Lindberg ME, et al. Current clinical coverage of Radiation Therapy Oncology Group-defined target volumes for postmastectomy radiation therapy. Pract Radiat Oncol. 2012;2:201-209. doi:10.1016/j.prro.2011.10.001

23. Chang CS, Chen CH, Liu KC, Ho CS, Chen MF. Selection of patients with left breast cancer for IMRT with deep inspiration breath-hold technique. J Radiat Res. 2020. doi:10.1093/jrr/rraa003

24. Zhang Q, Yu XL, Hu WG, et al. Dosimetric comparison for volumetric modulated arc therapy and intensity-modulated radiotherapy on the left-sided chest wall and internal mammary nodes irradiation in treating post-mastectomy breast cancer. Radiol Oncol. 2015;49:91-98.

25. Gagliardi G, Constine LS, Moiseenko V, et al. Radiation dose-volume effects in the heart. Int J Radiat Oncol Biol Phys. 2010;76:S77-S85. doi:10.1016/j.ijrobp.2009.04.093

26. Yee C, Wang K, Asthana R, et al. Radiation-induced skin toxicity in breast cancer patients: a systematic review of randomized trials. Clin Breast Cancer. 2018;18:e825-e840. doi:10.1016/j.clbc.2018.06.015

27. Vogelius IR, Bentzen SM. A literature-based meta-analysis of clinical risk factors for development of radiation induced pneumonitis. Acta Oncol. 2012;51:975-983. doi:10.3109/0284186X.2012.718093

28. Lind PA, Marks LB, Hardenbergh PH, et al. Technical factors associated with radiation pneumonitis after local \pm regional radiation therapy for breast cancer. Int $J$ Radiat Oncol Biol Phys. 2002;52:137-143. doi:10.1016/S0360-3016(01)01715-1
29. Omarini C, Thanopoulou E, Johnston SR. Pneumonitis and pulmonary fibrosis associated with breast cancer treatments. Breast Cancer Res Treat. 2014;146:245-258. doi:10.1007/s10549-014-3016-5

30. Marks LB, Yu X, Vujaskovic Z, Small W Jr, Folz R, Anscher MS. Radiation-induced lung injury. Semin Radiat Oncol. 2003;13:333-345. doi:10.1016/S1053-4296(03)00034-1

31. Overgaard M, Bentzen SM, Christensen JJ, Madsen EH. The value of the NSD formula in equation of acute and late radiation complications in normal tissue following 2 and 5 fractions per week in breast cancer patients treated with postmastectomy irradiation. Radiother Oncol. 1987;9:1-11. doi:10.1016/S0167-8140(87)80213-X

32. Kahan Z, Csenki M, Varga Z, et al. The risk of early and late lung sequelae after conformal radiotherapy in breast cancer patients. Int J Radiat Oncol Biol Phys. 2007;68:673-681. doi:10.1016/j. ijrobp.2006.12.016

33. Lind PA, Wennberg B, Gagliardi G, Fornander T. Pulmonary complications following different radiotherapy techniques for breast cancer, and the association to irradiated lung volume and dose. Breast Cancer Res Treat. 2001;68:199-210. doi:10.1023/A:1012292019599

34. Graham MV, Purdy JA, Emami B, et al. Clinical dose-volume histogram analysis for pneumonitis after 3D treatment for non-small cell lung cancer (NSCLC). Int J Radiat Oncol Biol Phys. 1999;45: 323-329. doi:10.1016/S0360-3016(99)00183-2

35. Blom Goldman U, Wennberg B, Svane G, Bylund H, Lind P. Reduction of radiation pneumonitis by V20-constraints in breast cancer. Radiat Oncol. 2010;5:99. doi:10.1186/1748-717X-5-99

36. Hong JC, Rahimy E, Gross CP, et al. Radiation dose and cardiac risk in breast cancer treatment: an analysis of modern radiation therapy including community settings. Pract Radiat Oncol. 2018;8:e79-e86. doi:10.1016/j.prro.2017.07.005

37. Dell'Oro M, Giles E, Sharkey A, Borg M, Connell C, Bezak E. Study of radiotherapy patients with left-sided breast cancer; patient selection criteria for deep inspiration breath hold technique. Cancers. 2019;11(2):259. doi:10.3390/cancers11020259

38. Das IJ, Andrews JZ, Cao M, Johnstone PA. Correlation of 2D parameters to lung and heart dose-volume in radiation treatment of breast cancer. Acta Oncol. 2013;52:178-183. doi:10.3109/0284186X.20 12.673737

39. Taylor C, Correa C, Duane FK, et al. Estimating the risks of breast cancer radiotherapy: evidence from modern radiation doses to the lungs and heart and from previous randomized trials. J Clin Oncol. 2017;35(15):1641-1649. doi:10.1200/JCO.2016.72.0722

40. Sardaro A, Petruzzelli MF, D’Errico MP, Grimaldi L, Pili G, Portaluri M. Radiation-induced cardiac damage in early left breast cancer patients: risk factors, biological mechanisms, radiobiology, and dosimetric constraints. Radiother Oncol. 2012;103:133-142. doi:10.1016/j.radonc.2012.02.008

\section{Publish your work in this journal}

Cancer Management and Research is an international, peer-reviewed open access journal focusing on cancer research and the optimal use of preventative and integrated treatment interventions to achieve improved outcomes, enhanced survival and quality of life for the cancer patient.
The manuscript management system is completely online and includes a very quick and fair peer-review system, which is all easy to use. Visit http://www.dovepress.com/testimonials.php to read real quotes from published authors. 